\title{
Energy Performance of Public Lighting
}

\begin{abstract}
After energy performance of lighting in buildings assessed in the proces of energy certification was put to life few years ago, the focus is now on energy performance of public lighting. As required by the mandate of the European Commission to the CEN to define and introduce suitable numerical indicators of the energy performance of public lighting systems, the standardisation process started in 2009. A self standing part of the standard for roadlighting, prEN13201-5 in particular, is devoted to this topic. This standard actually passed through the formal vote in CEN and release of the standard is expected in August this year. Since the begin there were several indicators like LENI, SLEEC and others under discussion, but finally a pair of compound indicators PDI and AECI won the battle. It is obvious that situation in road lighting is principially different from buildings and this fact has to be reflected in selection and definition of the indicators.

Aim of this paper is to explain the different approaches and reasons of the selection of PDI and AECI as indicators for assessment of public lighting systems and to give an overview on the main parts of this draft standard with discussion on practical application of the indicators. Lighting control profiles important for calculation of the annual energy consumption incorporated in the AECI indicator are discussed as well in the paper.
\end{abstract}

Keywords: road lighting, public lighting, energy efficiency, energy performance, PDI, AECI

\section{Introduction}

Energy efficiency of lighting systems belongs to one of the most discussed topics in lighting engineering today ${ }^{[1],[2],[16]}$. Satisfying required lighting quality criteria as pre-condition, lighting systems should be also designed with respect to the least energy consumption and optimized investment/operational costs. Energy demand is in close relation with carbon dioxide emissions, decrease of which is a global target ${ }^{[3]}$. Energy saving measures concern both existing and new objects and can be divided to product oriented and system oriented. In the field of lighting, system based legislative ${ }^{[4]}$ and normative ${ }^{[5]}$ measures are well developed and actually being improved for energy performance of buildings. Energy efficiency criterion is here represented by the well-known numerical indicator LENI ${ }^{[5]}$. For public lighting systems there are several approaches and assessment systems published up to now ${ }^{[8],[9]}$. The mainstream approach is equivalent to LENI used for buildings, i.e. based on $\mathrm{kWh}$ per meter square of the area to be lit. Unlike in buildings where the indicator has to be combined with other sub-systems, in public lighting there are no such restrictions and the indicator can be related also to the lighting level. Numerical indicators for the assessment of energy performance of public lighting systems are now officially established in the draft standard prEN13201-5 $5^{[7]}$. After years of hard discussions in the corresponding CEN workgroup, the document successfully passed through the Formal Vote in CEN and now it is being prepared for publication. The standard comprises informative parts to ease the understanding how the pair of indicators have to be calculated and what values one can expect, depending on road profile, road width, lighting class and lamp type.

\section{Energy performance indicators}

Until the standardization on energy performance of public lighting began, several approaches on assessment of energy efficiency were known. Further concepts have been elaborated during the standardization process. Concepts and approaches have been summarized in several publications ${ }^{[8],[9]}$ and they are briefly listed here:

- Installed power per road length $P_{\mathrm{L}}$ in $\mathrm{kW} / \mathrm{km}$ : Used in many of available lighting software. This indicator does not consider different road widths. It is calculated from the system power of luminaire used and number of luminaires per kilometre taken from spacing of the installation.

- Installed power per road area $P_{A}$ in $W / m^{2}$ : Used in many lighting software. It is a simple power density.
- Lighting Energy Numerical Indicator LENI in $\mathrm{kWh} / \mathrm{m}^{2}$ : Approach inherited from the EPBD is today used provisionally in some countries or by some experts. However, there is no methodology how to take into calculations the lighting control because situation in buildings, for which the LENI concept was derived, is different.

- Street Lighting Energy Efficiency Criterion SLEEC in $\mathbf{k W h} / \mathbf{l x} / \mathbf{m}^{2}$ : This is the most complex indicator that integrates all the necessary factors - lighting control and operational profiles, photometric parameter and area of the illuminated target. Nevertheless, this indicator in its complexity failed to succeed in scaling as resulting figures did not reliably distinguish between worse and better installations, what concerns their energy efficiency.

- Power Density Indicator PDI in W/Ix/m $\mathrm{m}^{2}$ and Annual Energy Consumption Indicator AECl in $\mathrm{kWh} / \mathrm{m}^{2}$ : This pair of compound indicators is finally established in prEN13201-5. The previous SLEEC concept is here split into two indicators that should alway be used together. PDI stands for istalled power density while AECI expresses the energy consumption density.

- Luminous efficacy $\boldsymbol{\eta}$ in $\mathrm{Im} / \mathbf{W}$ : This alternative approach is reciprocal to the previously mentioned indicators, with different input data. Luminous efficacy of the lighting installation accounts for losses of luminous flux along path from the lamp to the illuminated target and comprises of efficacy of the lamp, optical efficiency (L.O.R.) of the luminaire, maintenance factor (MF) and utilisation factor (UF). Luminous efficacy of the public lighting installation is introduced in prEN13201-5 as an additional informative parameter

- Other approaches: Besides the main stream concepts, there are also other studies performed by different authors, e.g. [10].

Except of luminous efficacy, the indicators are based on three main inputs:

- System power of luminaires (W): Power of all components associated with the illuminated area and necessary for the functioning of the system shall be included in calculation, i.e. power of lamps, ballasts, control gears, drivers, lighting controls etc. If for calculation an elementary area of road section between two consecutive luminaires is considered, identical to the calculation field, only power of one of the luminaires is to be included (or half of the two luminaires).

- Area as a target of illumination $\left(\mathrm{m}^{2}\right)$ : In general it can be an elementary area identical to the calculation field or 
it can be a full length of the lighting installation - in case of straight roads. Indicators are applicable also for any areas of regular or irregular shape like squares, parks, pedestrian walk zones etc.

- Luminous parameter (usually Ix): Discussed variants split between luminance (in cd. $\mathrm{m}^{-2}$ ) and illuminance (in Ix) based indicators or their combination into single lux based indicator where lluminance can be for the sake of simplicity transformed to illuminance through the luminance coefficient $Q_{0}$. Having slight loss of advantages of luminance optimized lighting designs, this enables to combine e.g. sidewalks (illuminance based classes) and carriageways (luminance based classes) lit by the same lighting arrangement and to calculate an energy performance indicator for such a lighting system. Another discussed question is whether specified, target or calculated values should be used. The normative concept accounts for the values of illuminance calculated directly on all target surfaces.

According to the European standard EN13201-5, energy performance of public lighting (officially: road lighting) systems is expressed by means of two numerical indicators - Power Density Indicator (PDI) and Annual Energy Consumption Indicator $(\mathrm{AECl})$. PDI shall be always presented and used together with the values of $\mathrm{AECl}$ for assessment of the energy performance of a particular lighting system.

Power density indicator (PDI) for an area divided into subareas can be calculated with the following formula:

$$
D_{P}=\frac{P}{\sum_{i=1}^{n} \overline{E_{i}} \cdot A_{i}}
$$

where $D_{\mathrm{P}}$ - power density indicator $\left(\mathrm{W} . \mathrm{Ix}^{-1} \cdot \mathrm{m}^{-2}\right), P$ - system power of the lighting installation used to light the relevant areas (W), $E$ - calculated maintained average horizontal illuminance (Ix), $A_{\mathrm{i}}$ - size of the sub-area "i" lit by the lighting installation $\left(\mathrm{m}^{2}\right), n-$ number of sub-areas to be lit.

For illuminance based lighting classes ( $C$ and $P$ ) the maintained average horizontal illuminance $E_{\mathrm{i}}$ shall be calculated according to EN 13201-3. For luminance based lighting classes $(\mathrm{M})$ the maintained average horizontal illuminance $E_{\mathrm{i}}$ shall be the average of illuminance values calculated on the same grid of points which are used for the calculation of luminance in accordance with EN 13201-3 ${ }^{[6]}$. Using specified or target values of illuminance it can be impossible, in some situations, to compare lighting systems with the fixed geometry (e. g. refurbishment) when none of the parameters differ. But using calculated values it is more difficult to prevent the overlit of the target surface and this is the reason why PDI should never be used stand alone but together with $\mathrm{AECl}$.

If the required lighting class changes during the night and/or through the seasons (e.g. reductions due to decreased traffic density, changes in the visual environment etc.), the PDI should be calculated separately for each of the lighting classes. It means that for the same lighting installation several values of PDI can be provided. The calculation must clearly indicate the assumptions used for calculation of the power density and how this value was evaluated.

Annual Energy Consumption Indicator (AECI) shall be calculated with the following formula:

$$
D_{E}=\frac{\sum_{j=1}^{m} P_{j} \cdot t_{j}}{A}
$$

where $D_{\mathrm{E}}$ - annual energy consumption indicator for a road lighting installation (Wh.m $\left.{ }^{-2}\right), P_{\mathrm{j}}-$ operational power associated with the $\mathrm{j}^{\text {th }}$ period of operation $(\mathrm{W}), t_{\mathrm{j}}$ - duration of jth period of operation profile when $P_{\mathrm{j}}$ is consumed, over a year (h), $A$ - size of the area lit by the same lighting arrangement $\left(\mathrm{m}^{2}\right), m-$ number of periods with different operational power $P_{\mathrm{j}}$

$m$ shall also consider the period over which the quiescent power is consumed. This period would generally be the time when the lighting is not operational i.e. daylight hours and any night time period when the lighting is not lit.

If the light output of a light source is intended to be constant, but the power consumption varies in time (e.g. using constant light output drivers), the average power consumption over the anticipated lifetime must be included in the calculation. Lifetime assumptions used for calculation of the average power consumption and evaluation of its value must be clearly indicated.

\section{Overview of the European standard prEN 13201-5}

Main purpose of the standard prEN 13201-5 is to define energy performance indicators for road lighting installations and to specify how to calculate them. Power density indicator PDI demonstrates the energy needed for a road lighting installation, while it is fulfilling the relevant lighting requirements specified in EN 13201-2 ${ }^{[6]}$. The annual energy consumption indicator $\mathrm{AECl}$ determines the power consumption during the year, even if the relevant lighting requirements change during the night or seasons. These indicators may be used to compare the energy performance of different road lighting solutions and technologies for the same target road. Energy performance of road lighting systems with different road geometries or different lighting requirements cannot be compared to each other directly what is explicitly mentioned in the standard.

Main body of the standard, introducing PDI and $\mathrm{AECl}$ and specifying requirements for their calculation as well as determination of the system power, area to be lit and average illuminance aver that area in dedicated subclauses, is completed by four informative annexes containing further useful information as described below:

ANNEX A: Examples of operational profiles and examples of calculation of the energy performance indicators are provided in this annex. Typical values values of energy performance indicators are also provided to illustrate the energy performance of recent technological level of luminaires and installations.

ANNEX B introduces the installation luminous efficacy and its factors as a measure of the influence of various light losses and other parameters. This method is recognized as reciprocal to the PDI/AECl approach and it was hardly discussed which of them prefer as normative. Finally it was resolved that only one can be selected as normative to avoid duplicity or confusion and the priority was given to the approach equivalent to LENI for the energy performance of buildings. Thus, luminous efficacy can be calculated additionally to PDI and AECI.

ANNEX C: Lighting factor of an installation is introduced. It can be additionally used to characterise the energy performance of road lighting installations independently on the lighting components used. Other factors and parameters having influence to the energy performance, as such as the maintenance factor, can be recognized but not dealt in this standard.

ANNEX D: Recommendations on presentation of the energy performance indicators are provided here. All values and assumptions taken for the calculation of energy performance indicators should also be displayed clearly 
with the indicators. An example is given in a form of a table. In some cases graphical interpretation of the operationa profile can be a suitable way of presentation.

\section{Lighting control profiles}

For calculation of $\mathrm{AECl}$ it is necessary to assume some lighting control profile. Typical examples of daily operational profiles for road lighting are presented in the informative Annex A.1 of the standard prEN 13201-5. However, start time and end time of operation change throughout the year and depend on the geographical latitude and local conditions. It is advisable that the operation of artificial lighting is correlated with illuminance from daylight with respect to the illuminance required for a particular lighting class. In the moment of sunset the illuminance level is considerably high but rapidly decreases. At sunrise the situation is reversed ${ }^{[11]}$. For calculation of $A E C l$ it is necessary to sum up daily operation hours for each of the lighting levels throughout a whole year ${ }^{[12]}$.

Examples of operational profiles shown below in Fig. 1 - 4 illustrate the daily course of lighting level. Power level needed for the calculation of energy performance is associated with lighting levels depending on lamp type, lamp power and other factors. Parasitic power is an additional component that should be included in the calculation of $\mathrm{AECl}$.

a) Full power operation (Fig. 1): This profile is typical for lighting installations with simple switching devices like time switchers or photosensors. Luminaires operate constantly at full power throughout the night time each day. The full power profile is typical for most of the existing lighting systems. In new systems it should be used only where constant traffic is supposed.

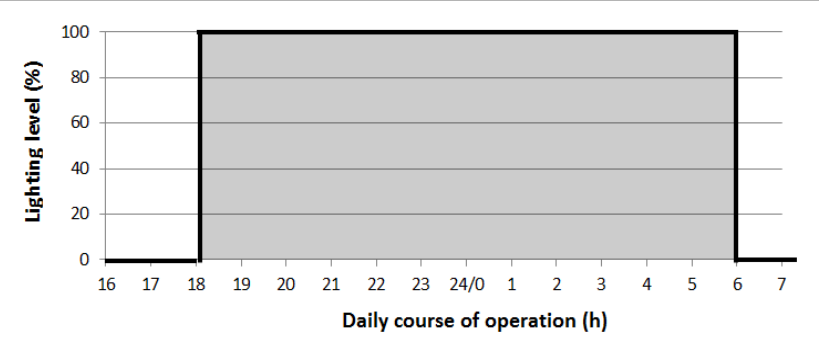

Fig.1. Full power operational profile

b) Multi-power operation (Fig. 2): The multi-power profile (e. g. bi-power profile shown in Fig. 2) consist of two or more time periods during the daily course when luminaires are operated at different power associated with different lighting levels provided. Each of the lighting levels should be derived from lighting class according to EN 13201-2. This profile is suitable for most of roads where lower traffic density during night-time can be expected. During period of the reduced lighting level, a dedicated lighting class to EN 13201-2 should be derived.

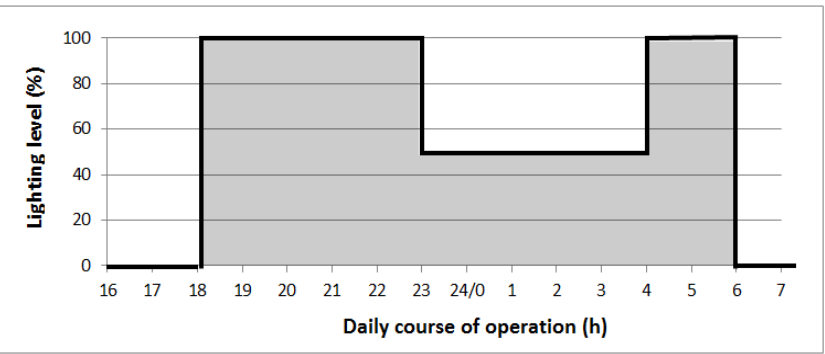

Fig.2. Bi-power operational profile
To dim the light, voltage regulators, self-controlled ballasts or similar devices can be used.

c) Nighttime blackout (Fig. 3): This profile is sometimes used for energy saving reasons in systems with simple switching devices where reduction of lighting to a lower level is technically not possible. Though not advisable for safety reasons, this profile is applicable to small installations in the immediate vicinity of astronomic observatories. The nighttime blackout is not listed amongst examples of daily operational profiles in the standard prEN13201-5 in order not to promote this option due to loss of service with a risk to jeopardize the traffic and/or personal safety.

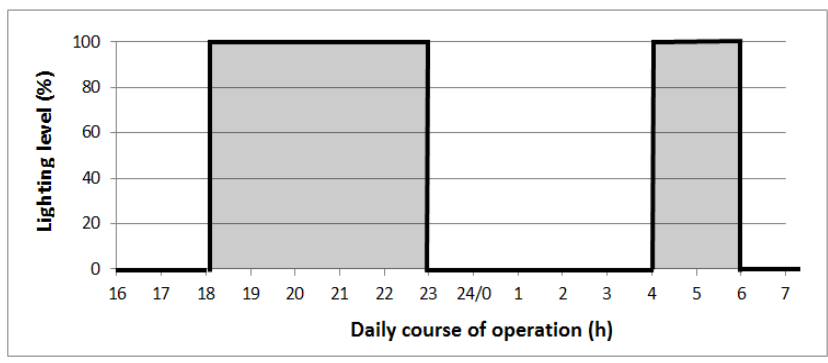

Fig.3. Nighttime blackout

d) Operation with vehicle and presence detectors (Fig. 4): If vehicle and/or presence detectors are used to control the lighting system, full power or multi-power operational profiles are truncated by time periods when no traffic is sensed by the associate detectors and luminaires operate at reduced levels. Fig. 4 shows and example of tripower operational profile for lighting control with detectors where at least a minimum lighting level is kept throughout the night time. Peaks depicted in Fig. 3 depend on sensing and are not periodical. For calculation of $\mathrm{AECl}$ it is necessary to assume for annual probability parameter for each of the lighting levels. By means of smart grids with detectors and in combination with easy-to-dim light sources like LEDs it is highly efficient to provide lighting in levels and times when it is really needed. Similarly to the bi-power operation with full level and reduced level lighting, an additional minimum maintained level is defined in the tripower operation profile rather than to switch off the lighting. This profile is particularly suitable for residential areas.

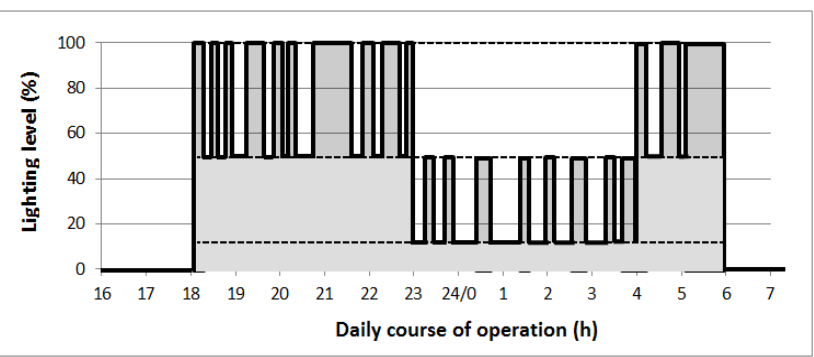

Fig.4. Tri-power detector-driven operational profile

For the full power operational profile it is common to take the annual operation time 4000 hours. To consider different operational profiles it is usually sufficient to combine the annual operation times of individual lighting levels with the associated system power and the detection probability (in systems with detectors) into a single lighting operation coefficient cop. This coefficient can be used to multiply the $\mathrm{AECl}$ for full power operation to obtain the value of $\mathrm{AECl}$ for other operational profile. Typical values of the lighting operation coefficient cop for different operational profiles 
are shown in Table 1, the values have been derived under these assumptions:

- Full power: 4000 hours operation at full power P;

- Bi-power: 2175 hours at full power P and 1825 hours at reduced power $0,7 \square \mathrm{P}$ with lighting level reduced to $50 \%$;

- Nighttime blackout: as for bi-power but with no operation during the period of 1825 hours (loss of service);

- Tri-power: 2175 hours of bi-level lighting control between $100 \%$ and $60 \%$ of the system power with detection probability of $80 \%$ and 1825 hours of reduced bi-level lighting control between $20 \%$ and $60 \%$ of system power with detection probability of $20 \%$.

Table 1. Typical values of the lighting operation coefficient for different operational profiles

\begin{tabular}{|l|c|}
\hline \multicolumn{1}{|c|}{ Operational profile } & cop $_{\text {on }} \%$ \\
\hline Flat full power & 100,0 \\
\hline Bi-power & 86,3 \\
\hline Nighttime blackout & 54,4 \\
\hline Tri-power with detectors & 62,8 \\
\hline
\end{tabular}

\section{Typical values of energy performance indicators}

In order to obtain bulk data for benchmarking energy performance indicators, vast number of sample calculations have been performed for the most common situations ${ }^{[9],[13]}$ The calculations did not yet cover all the options and research in this field still continues. However, the acquired data available to date of finalization of the standard have been processed and tabelized results of typical PDI and $A E C l$ values have been included in the informative Annex A.3 aiming to create an imagination on the indicators with respect to different conditions like the lamp type, road profile arrangement, lighting class considered and width of the carriageway and sidewalks. For practical reasons the $\mathrm{PDI}$ is presented in smaller units, i.e. $\mathrm{mW} \cdot \mathrm{Ix}^{-1} \cdot \mathrm{m}^{-2}$.

Assumptions taken into account for sample calculations are as follows:

- width of sidewalks and grass strips, where applicable, equals to $2 \mathrm{~m}$

- maintenance factor is set to 0,80 for all types of lamps and luminaires

- for road reflection properties the R3 table is considered

- mounting height is optimized within the range 5 to $12 \mathrm{~m}$ (step: whole numbers)

- spacing of lighting poles is optimized and sought between 20 to 60 m (step: $1 \mathrm{~m}$ )

- arm overhang is ranged from 0 to $2 \mathrm{~m}$ with the (step: $0,5 \mathrm{~m}$ )

- luminaires are not tilted

- annual operation time 4000 hour at full power

Arrangement of the lighting system is generally single-sided and for some situations with wider carriegeway an opposite arrangement is selected. For each calculation, the lighting system geometry is optimized with preference given to the spacing in order to enlarge the illuminated area as much as possible and to have thus the energy performance indicators as low as possible. Mounting height and arm length affects to the indicators only indirectly.

Luminaires used in calculations cover the possible options. Low-cost or sophisticated luminaires incorporate reflecting diffuser or high-quality smooth or faceted reflectors, respectively. Lamp types comprise ellipsoidal and tubular high-pressure sodium lamps, mercury lamps, metal halide lamps and LEDs of different wattages. Lamp position in the luminaire, where adjustable, is optimized and not taken as an option. Calculations are based on lighting products (luminaires) available in Q1/2014.

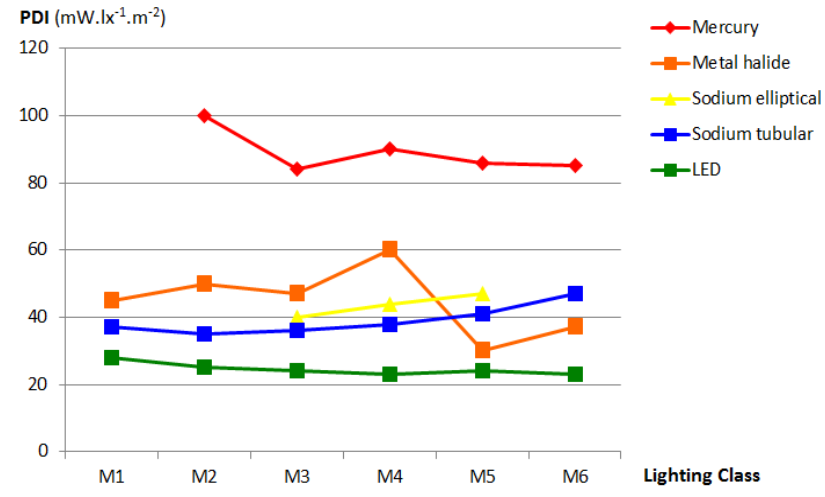

Fig.5. Typical PDI values for road profile A and road width of $7 \mathrm{~m}$

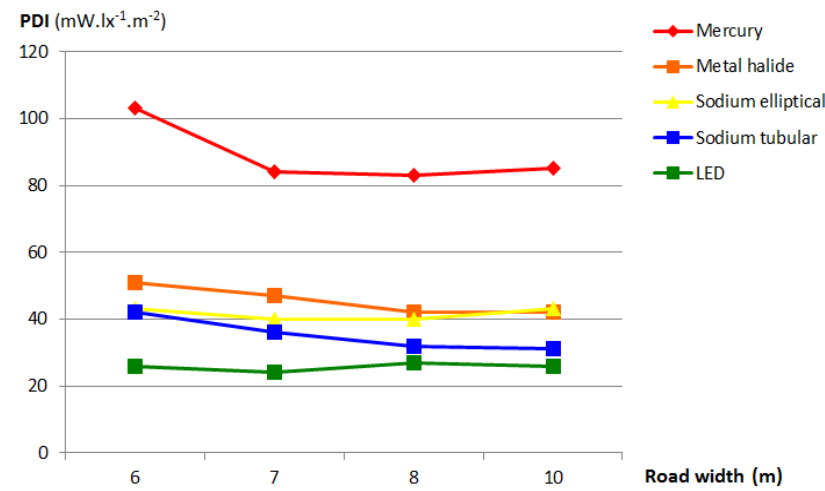

Fig.6. Typical PDI values for road profile A and lighting class M3

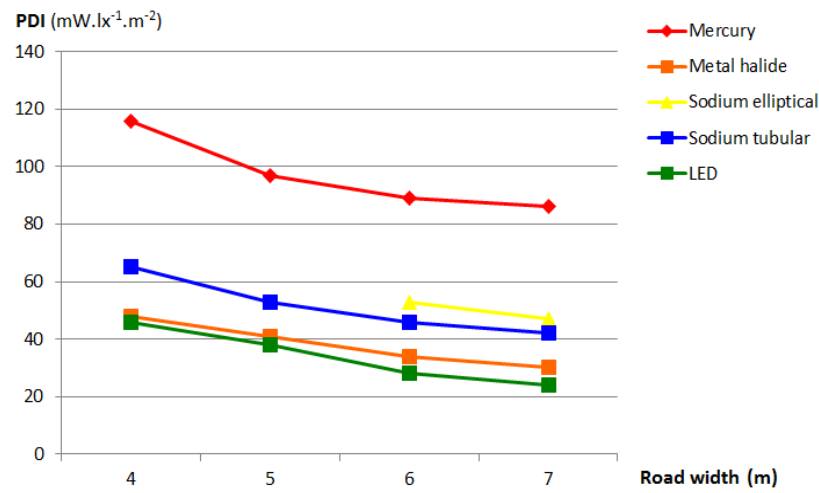

Fig.7. Typical PDI values for road profile $A$ and lighting class M5

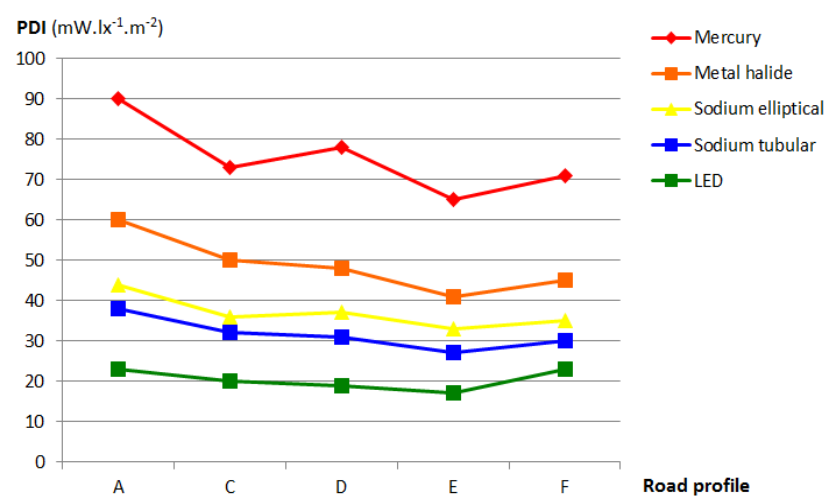

Fig.8. Typical PDI values for road width of $7 \mathrm{~m}$ and lighting class M4

The lower is the value of PDI and AECl, the better energy performance. The values should not be used as benchmarks, they are intended to create an imagination on absolute values of the indicators and their variation and to aid how to distinguish between more and less energy efficient solutions. 
Typical PDI values versus different parameters and for different lamp types are shown below. Fig. 5 illustrates how PDI varies according to the lighting class (M). How PDI depends on road width, is depicted in Figures 6 and 7 for a road without sidewalks for two most common lighting classess M3 and M5 (assuming M4 as an inter-level). Finally, Fig. 8 represents the variation of PDI according to road profile where the M4 class and road width $7 \mathrm{~m}$ have been taken as common values.

In-depth analysis of the graphs in Figs. 5-8 is out of scope of this paper. Most of the curves seem to be flat but at close-up look and taking into account the individual calculation results it can be found out that minimum PDI values are obtained for roads with concurrent sidewalks, lighting classes $M 4$ and $M 3$ and the road width 7 to 8 metres. This is valid particularly for more sophisticated luminaires with high-quality and/or adjustable optics. Luminaires with diffuse reflectors have more significant light losses and thus worse PDI. Lamp type has an evident and expectable influence to the value of PDI.

\section{Preliminary proposals for energy class margins}

Energy scales for the assessment of energy performance of public lighting have been already proposed e.g. in [14], [15] and for the PDI/AECI approach in [13] (see Tab. 2). Looking at Figs. $5-8$ it is clear that to build reliable and widely acceptable scales it might be necessary to carry out more sample calculations and to perform more analyses of the results. Instead of even distribution of the typical PDI (or $\mathrm{AECl}$ ) values it is advisable to define conditions that each of the energy class should fulfil. For example:

- bottom margin of the $B$ class should be the least acceptable level for new lighting systems

- bottom margin of the D class should be the $50 \%$ of all existing installed systems in average

Table 2. Preliminary proposal of scaling the energy performance indicators

\begin{tabular}{|l|c|c|c|c|c|}
\hline $\begin{array}{l}\text { Energy } \\
\text { Class }\end{array}$ & $\boldsymbol{P}_{\mathrm{L}}$ & $\boldsymbol{P}_{\mathbf{A}}$ & SLEEC & PDI & AECl \\
\cline { 2 - 6 } & $\mathrm{kW} / \mathrm{km}$ & $\mathrm{W} / \mathrm{m}^{2}$ & $\mathrm{kWh} / \mathrm{lx} / \mathrm{m}^{2}$ & $\mathrm{~W} / \mathrm{lx} / \mathrm{m}^{2}$ & $\mathrm{kWh} / \mathrm{m}^{2}$ \\
\hline A - B & $\leq 4$ & $\leq 0,35$ & $\leq 0,10$ & $\leq 28$ & $\leq 1,4$ \\
\hline C - D & $4-6$ & $0,35-0,5$ & $0,10-0,15$ & $28-34$ & $1,4-2$ \\
\hline E - F & $6-8$ & $0,5-0,75$ & $0,15-0,20$ & $34-40$ & $2-3$ \\
\hline G & $\geq 8$ & $\geq 0,75$ & $\geq 0,20$ & $\geq 40$ & $\geq 3$ \\
\hline
\end{tabular}

${ }^{*} \mathrm{AECl}$ values for flat full power operation of $4000 \mathrm{~h}$ applied to the same systems as for PDI

\section{Conclusions}

As mentioned above, it is difficult (if not impossible) to mutually compare lighting systems or lighting solutions for different road geometries or different lighting requirements. Then it is a question whether it is feasible to compose energy scales for public lighting systems. Of course, there is always an option to have more scales, e. g. separately for different lighting classes, but on the other hand, the scales should be simplified as much as possible. Flat nature of most of the curves in Fig. 5 to Fig. 8 promises that standard energy scales can be real. It is necessary to have in mind that CEN have got the mandate to define standard energy performance indicators from the European Commission, i. e. the indicators are possibly inteded to be used for energy labelling purposes just like LENI for the buildings.

The new European standard EN 13201-5 successfully passed through the Formal Vote and it is expected to be published in August 2015. Afterwards, the indicators should penetrate to the lighting practice. It is desirable to have the energy performance indicators presented together with results of the photometric calculation directly in the calculation software.

\section{REFERENCES}

[1] SKODA, J. \& BAXANT, P. The reduction in electricity consumption through proper lighting. In proc.: EPE - Electric Power Engineering 2009. Brno University of Technology: Brno, pp. $1-4$

[2] SOKANSKY, K. \& NOVAK, T.: Energy savings in public lighting. Przeglad Elektrotechniczny, 84(8), pp. 72 - 74, 2008

[3] United Nations Framework Convention on Climate Change. UN: Rio de Janeiro, 1992

[4] Directive No. 2010/31/EC of the European Parliament and of the Council on Energy Performance of Buildings. Brussels, 2010

[5] EN 15193:2007 Energy performance of buildings. Energy requirements for lighting

[6] EN 13201: Road lighting (group of standards), 2004

[7] prEN 13201-5:2013: Road lighting -Part 5: Performance requirments, 2014-07-23

[8] GAŠPAROVSKÝ, D., SCHWARCZ, P., JANIGA, P.: Assessment and Measurement of Energy Demand and Efficiency in Public Lighting Networks. In: "Light in Engineering, Architecture and the Environment", "(Poznan, Poland), 17.-19.5.2011. - Southampton (UK): WIT Press, 2011. ISBN 978-1-84564-550-2. - pp. 133 - 145

[9] GAŠPAROVSKÝ, D.: Energy Performance Numerical Indicators of Public Lighting. In: "Svetlo - Light 2013", (Podbanské, Slovakia), 23.-25.10. 2013. - Bratislava KONGRES Management s.r.o., 2013. - ISBN 978-80-8927535-9. - pp. $291-301$

[10] PRACKI, P.: A proposal to evaluate road lighting energy efficiency. In proceedings: "Lumen V4", Bratislava KONGRES Management s.r.o., 2012. ISBN 978-80-89275-328. - pp. $28-39$

[11] GAŠPAROVSKÝ, D.: Measurement of Daylight Illuminance Levels in Transient Periods for Public Lighting Control. In: Przeglad elektrotechniczny. - ISSN 0033-2097. - Vol. 89, Iss. 6 (2013), pp. $320-323$

[12] GAŠPAROVSKÝ, D.: Calculation of the Operation Time of Road Lighting. In: Proceedings of CIE Centenary Conference "Towards a New Century of Light" : Paris, France, 15-16 April 2013. - Vienna : Commission Internationale de l'Eclairage, 2013. - ISBN 978-3-902842-44-2. - pp. 999 - 1008

[13] GAŠPAROVSKÝ, D., DUBNIČKA, R., RADITSCHOVÁ, J.: Benchmarking the energy efficiency of road lighting. In: Proceedings of CIE Conference "Lighting Quality and Energy Efficiency": Kuala Lumpur, Malaysia, 23-26 April 2014. Vienna : Commission Internationale de l'Eclairage, 2014. ISBN 978-3-902842-49-7.

[14] PRACKI, P.: Poposal to classify road lighting energy efficiency. In: Lighting Research and Technology. - ISSN: 1477-0938. Vol. 43, Iss. 3 (2011), pp. $271-280$

[15] PRACKI, P.: Unified system of lighting energy efficiency evaluation in public places. Proceedings of CIE Conference "Lighting Quality and Energy Efficiency": Vienna, Austria, Vienna : Commission Internationale de l'Eclairage, 2010. ISBN 978-3-901906-83-1. - pp. 317 - 321

[16] BOYCE, P.R., FOTIOS, S., RICHARDS, M.: Roadlighting and energy saving. In: Lighting Research and Technology. - ISSN: 1477-0938. Vol. 41, Iss. 3 (2009), pp. $245-260$

Authors: Doc. Ing. Dionýz GAŠPAROVSKÝ, PhD., Slovak University of Technology, Faculty of Electrical Engineering and Information Technology, Ilkovicova 3, 81219 Bratislava, Slovakia, e-mail: dionyz.gasparovsky@stuba.sk 